\title{
Práticas pedagógicas digitais: o Facebook e a sala de aula invertida na formação dos alunos do ProfLetras
}

\author{
Digital pedagogical practices: Facebook and the inverted \\ classroom in the formation of ProfLetras students
}

\author{
Cicero Nestor Pinheiro Francisco* \\ professornesstor@gmail.com \\ Universidade Federal Rural de Pernambuco \\ Robson Santos de Oliveira \\ robssantoss@yhoo.com.br \\ Universidade Federal Rural de Pernambuco
}

\begin{abstract}
RESUMO: Este artigo objetiva discutir a importância da sala de aula invertida nos processos pedagógicos em um curso de pós-graduação (ProfLetras), destacando-se que este modelo de ensino impulsiona significativamente a aprendizagem e favorece as práticas colaborativas. A pesquisa mostra a importância que este modelo traz, aliada à tecnologia da rede social virtual do Facebook e à mediação docente, com ganhos significativos na realização de trabalhos pedagógicos, caracterizando-se como um modelo híbrido que não destitui o modelo tradicional de aula. Esse desenho didático-metodológico pode proporcionar uma adequada interação entre professores e alunos, assim como entre os próprios alunos de pós-graduação, proporcionando uma aprendizagem significativa, utilizando os recursos tecnológicos da internet. A pesquisa caracteriza-se como exploratório-descritiva, de abordagem quantitativa, com método de coleta de dados por meio do estudo de campo.
\end{abstract}

PALAVRAS-CHAVE: Sala de aula invertida. Facebook. Aprendizagem híbrida. Mestrado ProfLetras.

ABSTRACT: This article aims to discuss the importance of the inverted classroom model in pedagogical processes in a course of the graduate program ProfLetras, emphasizing that this model of teaching significantly boosts learning and promotes collaborative practices. This research shows the importance of this model as it combines the technology of Facebook, the virtual social network, and teaching mediation, showing significant gains in conducting pedagogical work, characterized as a hybrid model that is not deprived of traditional models of classes. This didacticmethodological design can provide adequate interaction between teachers and

\footnotetext{
* Mestrando do Programa de Pós-Graduação em Letras (ProfLetras) da Universidade Federal Rural de Pernambuco (UFRPE) na Unidade Acadêmica de Garanhuns (UAG)

Doutor em Psicologia Cognitiva e professor do Programa de Pós-Graduação em Letras (ProfLetras) da Universidade Federal Rural de Pernambuco (UFRPE) na Unidade Acadêmica de Garanhuns (UAG)
} 
students and among graduate students themselves, providing them with meaningful learning that uses the technological resources of the Internet. The research is characterized as exploratory and descriptive; it is a quantitative approach to data collection in a field study.

KEYWORDS: Inverted classroom. Facebook. Hybrid learning. ProfLetras.

\section{A problemática em estudo}

Vários desafios aparecem quando a necessidade de se realizar um fazer pedagógico tem intenções sérias, pautadas na aprendizagem de todos os alunos envolvidos no processo. Segundo Valente (2014), a educação superior vem passando por obstáculos que põem em dúvida o ensino realizado por instituições superiores. Ele apresenta as críticas ao modelo de sala de aula tradicional, propondo, embasado em outros autores, um novo olhar para a educação, no qual o aluno possa ser sujeito ativo no processo de aprendizagem. Xavier (2007, p. 143), ao falar das práticas sociais, inclui também as digitais. Considerando os procedimentos de leitura e escrita (letramentos), ele mostra que tais práticas, além de inovadoras, possibilitam o surgimento de outras, também inovadoras.

Dentre as propostas consideradas por Valente (2014), destacamos a da sala de aula invertida, que não é novidade para a área das ciências humanas, cujos alunos têm como prática levar o material para casa, estudá-lo e discutir posteriormente nas aulas, verificando o que foi aprendido. Especificamos como inovadora a sua promoção através de ferramentas digitais. Neste modelo, a teoria é estudada em casa, no formato online, e o espaço da sala de aula é utilizado para discussões, resoluções de atividades, entre outras propostas do ensino híbrido (BACICH; TANZI; TREVISANI, 2015, p.54).

O ensino híbrido caracteriza-se pela alternância de atividades que são proporcionadas aos alunos em duas situações: uma parte dessas atividades é realizada em sala de aula, da maneira convencional; a outra é proporcionada através de recursos online. Nesta etapa o aluno escolhe como conduzir seu aprendizado, administrando questões como o local mais adequado ou tempo necessário para a execução de cada tarefa solicitada.

Segundo Oliveira (2015b, p. 151), trabalhar com determinadas ferramentas digitais exige "muito mais do(a) professor(a) para a realização de uma aula". Valente (2014) também apresenta razões de ordem teóricas e práticas ao mostrar por que se 
"deve" inverter a sala de aula. A obtenção dos elementos conceituais, neste caso, deve ser realizada em casa, onde os alunos podem ler, reler, fazer pesquisas complementares sobre o material estudado e, ao chegar à aula, através da interação com os professores e com os demais alunos, têm a possibilidade de socialização de conhecimentos e aprofundamento das questões, mediados pela prática docente.

Podemos falar sobre esta perspectiva que a relação ensino-aprendizagem caminha para uma "convergência digital", conceito também defendido por Pereira (2007), que prevê uma mudança na prática pedagógica, tanto por parte das instituições, que poderão fornecer conhecimento a um maior número de alunos, quanto aos próprios alunos, que poderão escolher em que hora e em que ambientes querem estudar. Encontramos essa abordagem vivenciada no Ensino Superior, conforme experiências didáticas apresentadas por Oliveira (2015a), ao usar as Redes Sociais Virtuais (RSV), como o antigo Orkut e o atual Facebook. O professor apresentou experiências exitosas ao usar a plataforma desses ambientes virtuais, na opção de comunidade (Orkut) e de grupo (Facebook) para realizar as atividades propiciadoras de modelo de sala de aula invertida. Compartilhamento de textos, vídeos, imagens, links bem como apresentação de questionários e socialização de resultados, enquetes ou informações gerais da disciplina são utilizados em tais ambientes, a fim de que, em sala de aula, presencialmente, os alunos possam participar mais intensamente do processo de ensino-aprendizagem mediados pelo docente.

A metodologia para a pesquisa aqui descrita caracteriza-se como exploratório-descritiva, quantitativa, com método de coleta de dados por meio do estudo de campo, pois, segundo Gil (2002, p. 53) "tipicamente, o estudo de campo focaliza uma comunidade, que não é necessariamente geográfica, já que pode ser uma comunidade de trabalho, de estudo, de lazer ou voltada para qualquer outra atividade humana". A coleta de dados foi realizada em 79 dias. Para efeito de análise, foram consideradas todas as publicações realizadas no grupo virtual do Facebook, e os resultados foram sistematizados em forma de gráficos.

O propósito deste trabalho é buscar mostrar como a ferramenta de criação de um grupo privado do Facebook tem sido usada também como ferramenta pedagógica no curso de Mestrado Profissional em Letras, evidenciando o conceito de sala de aula invertida, parecendo mostrar-se adequado na formação intelectual dos alunos. 


\section{ProfLetras na unidade acadêmica de Garanhuns}

O Profletras ${ }^{1}$ é um programa de mestrado em nível profissional para aprimoramento da carreira docente, ofertado em rede nacional. Um curso de pósgraduação stricto sensu oferecido por Instituições de Ensino Superior (IES) da rede pública e coordenado pela Universidade Federal do Rio Grande do Norte. Reúne 42 universidades públicas, presentes em todas as regiões brasileiras; entretanto, somam-se 49 unidades de ensino, já que quatro instituições oferecem o curso em mais de uma unidade de ensino.

A oferta do curso é específica para os professores de Língua Portuguesa, atuantes no Ensino Fundamental no Brasil. Regulamentado pela portaria de número 1.009 (de 10/10/2013), do Ministério da Educação, o curso oferece, entre outras, condições aos professores de se aperfeiçoarem com a intenção de melhorar a qualidade do ensino no país. O programa apresenta duas linhas de pesquisa: 1. Teorias da linguagem e Ensino; 2. Leitura e Produção textual: diversidade social e práticas docentes.

O ingresso dos alunos acontece por meio de provas com questões objetivas e discursivas.

A Universidade Federal Rural de Pernambuco (UFRPE), em sua Unidade Acadêmica de Garanhuns (UAG), oferta o Profletras desde 2015. Em 2016, a turma de aprovados para cursar o mestrado profissional, formada por 15 alunos, é composta por professores residentes nas seguintes cidades ${ }^{2}$ : Águas Belas $(1)^{3}$, Belém de São Francisco (2), Cabrobó (1), Caruaru (1), Garanhuns (3), Itamaracá (1), Maceió, AL (1), Petrolina (1), São Lourenço da Mata (1), Solidão (1), Tabira (1) e Tuparetama (1). Este dado confirma a singular importância que a formação proposta pela UFRPE/UAG possui para a região e até para outros estados.

O corpo docente do curso é formado por oito professores doutores, pertencentes ao corpo docente da instituição, e um professor doutor que participa como convidado/colaborador.

\footnotetext{
${ }^{1}$ Cf. http://www.profletras.ufrn.br/

${ }^{2}$ Localizadas em Pernambuco, com exceção da cidade de Maceió, localizada em Alagoas.

${ }^{3}$ Quantidade de alunos(as) aprovados(as).
} 
As aulas são presenciais, ofertadas durante dois dias por semana, com carga horária diária de oito horas-aula para cada dia. Também há a possibilidade de complementação da carga horária com a realização de atividades a distância.

Como exigido pelo programa, os alunos têm que cursar cinco disciplinas obrigatórias, três optativas e duas disciplinas de fundamentação, devendo obter, no final do curso, um total de 24 créditos (360 horas), num prazo de 24 meses.

Tendo em vista a diversidade geográfica e as possíveis dificuldades que docentes e discentes podem encontrar devido à distância entre suas residências e a IES, desde a primeira disciplina cursada, os professores lançam mão de ferramentas que auxiliam no processo de ensino-aprendizagem, visando estabelecer um melhor aproveitamento do curso.

A Unidade Acadêmica possui laboratórios de informática com acesso à internet, permitindo atividades em ambiente online mesmo durante as atividades presenciais.

\section{0 uso do grupo no Facebook para incremento dos trabalhos pedagógicos}

Dentre as ferramentas componentes das tecnologias digitais, as RSV têm ganhado bastante destaque: tanto pelo seu papel inovador, difusor, quanto por sua massiva popularização. Como o maior ambiente social virtual do mundo, o Facebook vem sendo utilizado no curso de mestrado ProfLetras da UAG.

Através do uso de redes virtuais há a possibilidade de encurtar distâncias e promover maior interação entre os participantes dos grupos, nelas inseridos, podendo, segundo Oliveira (2015b, p. 152), transformarem-se em Ambientes Virtuais de Aprendizagens (AVA). Este fato, que pode proporcionar um "alargamento" das fronteiras das IES, possibilita aos alunos maior interação com a IES, em especial na turma de mestrado aqui relatada. Na promoção do ensino, os professores têm usado o Facebook para possibilitar uma maior interação com os alunos, podendo estes fazer questionamentos, esclarecer dúvidas, receber materiais para estudo, entre outros.

No primeiro dia de aula de mestrado na UFRPE/UAG, os alunos foram convidados a entrar em um grupo privado do Facebook (criado pelo professor), com a finalidade de adquirirem os primeiros materiais de estudo. $O$ grupo foi nomeado: 
Profletras UFRPE/UAG Projetos e Tecnologia ${ }^{4}$ da disciplina de Elaboração de Projetos/Tecnologias Educacionais. Ali o professor apresentou a ementa da disciplina em formato digital, disponibilizando-a para download, assim como textos e links que seriam utilizados durante as aulas. Ainda nos primeiros encontros, os alunos também puderam enviar seus trabalhos.

Desde sua criação, datada de 10 de março de 2016, até o momento ${ }^{5}$, para efeito de corpus, foram contabilizadas as atividades realizadas no grupo num total de 133 postagens $^{6}$. Para uma melhor análise, separamos o teor das postagens de acordo com o assunto sobre a qual tratavam: avisos, materiais para estudo, fotos, etc. O resultado é o que representamos no gráfico abaixo:

Figura 1: Atividades postadas no grupo do Facebook

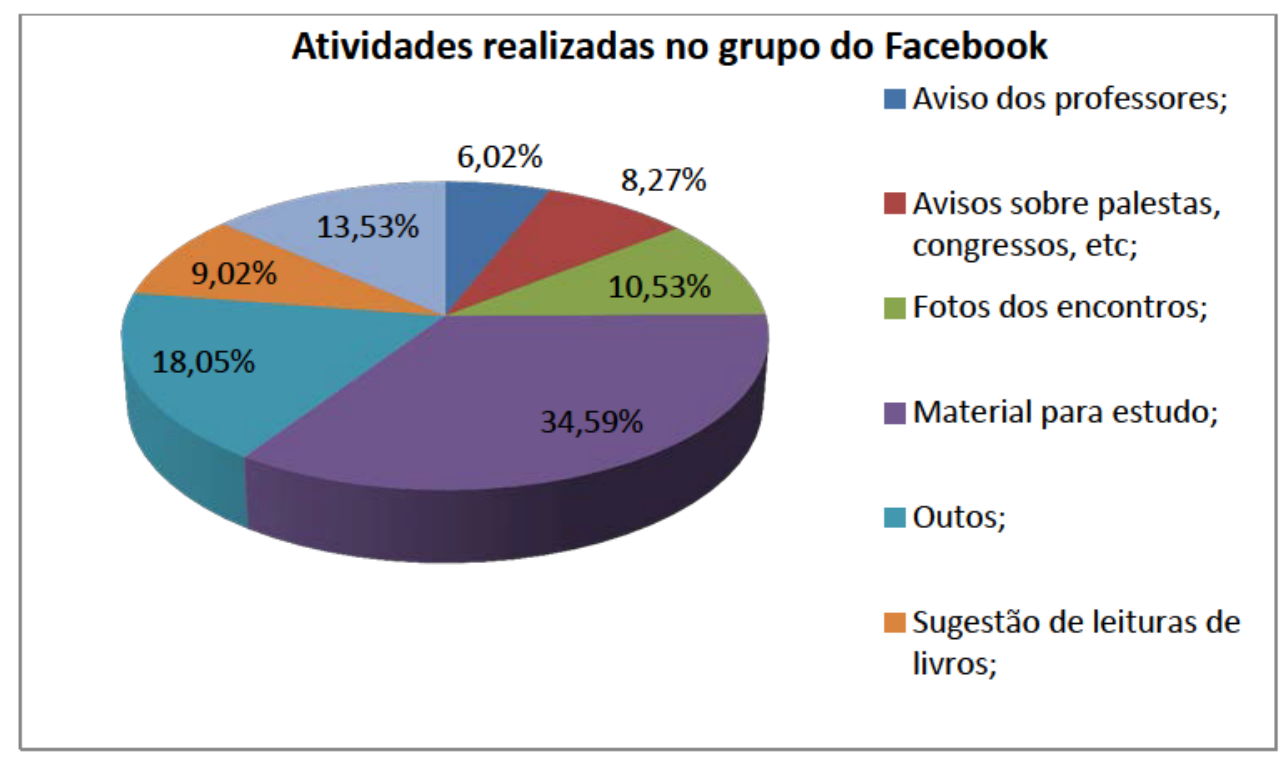

Para efeito de análise, ainda mais detalhada, categorizamos as atividades realizadas em dois subgrupos: 1 - atividades de teor pedagógico ${ }^{7}$ (materiais para estudo, avisos dos professores, trabalhos de alunos e sugestões de leituras); 2atividades de caráter informativo ${ }^{8}$ (avisos sobre palestras e congressos, fotos dos

\footnotetext{
${ }^{4}$ Disponível em https://www.facebook.com/groups/1897397920486460/. Acesso em 10/03/2016

${ }^{5}$ Leia-se 28 de maio de 2016.

${ }^{6}$ Não foram considerados os comentários realizados em cada postagem.

${ }^{7}$ Mensagens que incidem diretamente nas práticas pedagógicas do curso.

${ }^{8}$ Mensagens de cunho informativo geral da disciplina e do curso. Nesta categoria incluímos postagens de imagens diversas, conversas entre os alunos sobre aspectos diversos e vídeos ou animações publicadas com a intenção de descontrair
} 
encontros, outros). Para analisarmos a soma das atividades, separamos e analisamos as que foram realizadas por cada subgrupo. Vejamos o gráfico abaixo:

Figura 2: Atividades pedagógicas

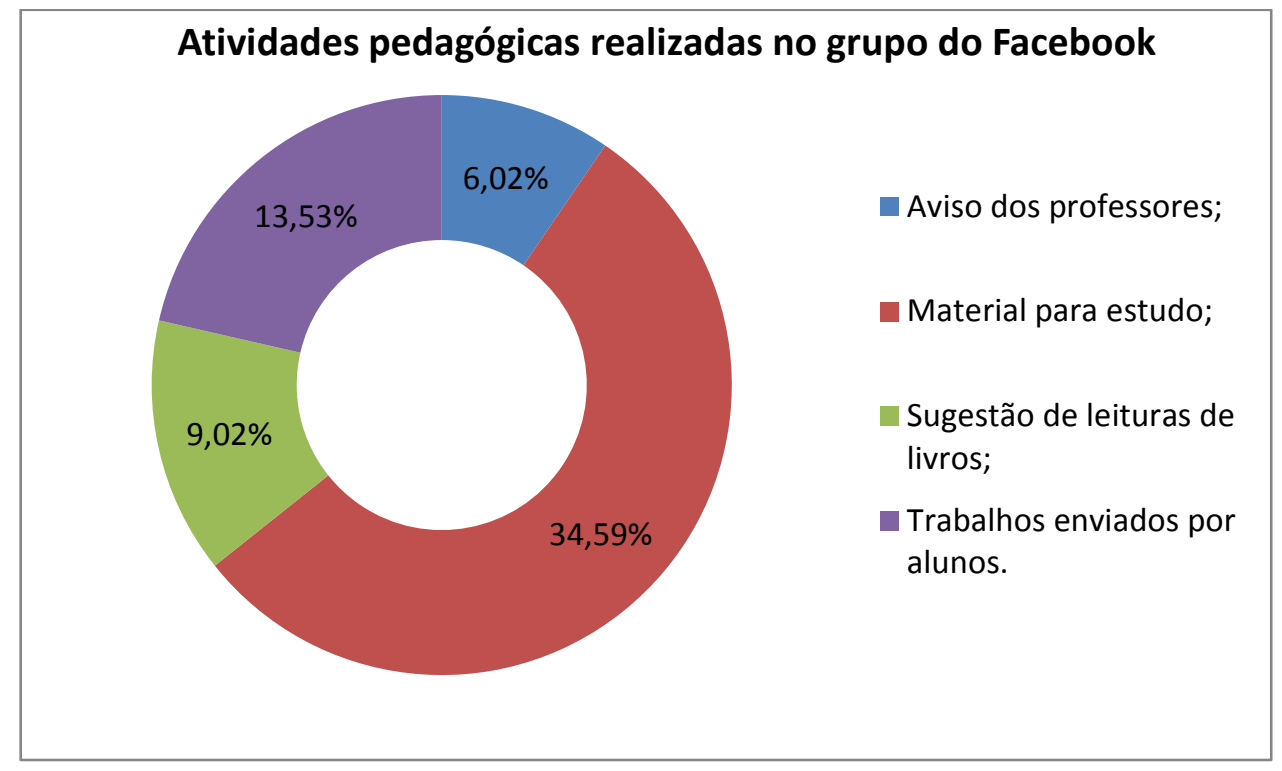

Como observado, as atividades que têm ligação direta com a prática pedagógica, totalizam um percentual de $63,16 \%$ das atividades realizadas no grupo (figura 2). Já as atividades informativas de cunho geral totalizam um percentual de $36,85 \%$, conforme pode ser notado no próximo gráfico:

Figura 3: Atividades informativas

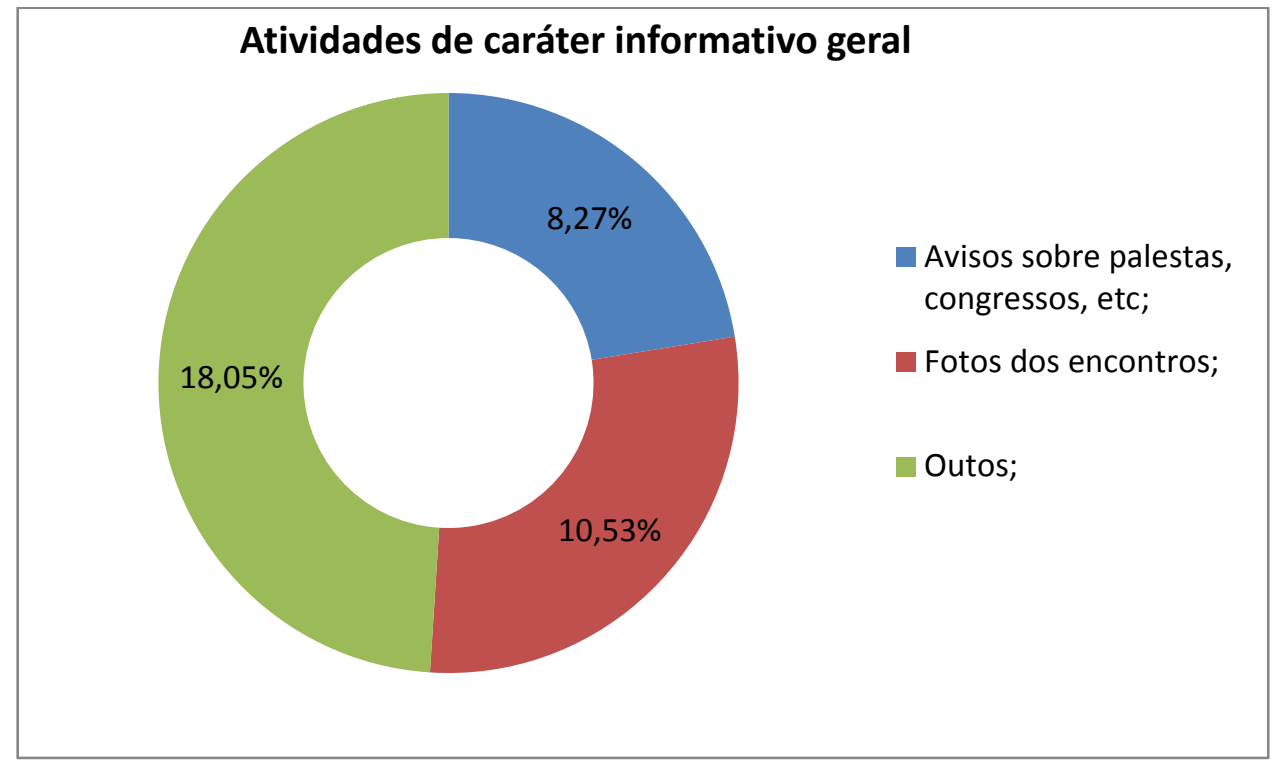


De acordo com os gráficos anteriores, para o caso em estudo, podemos comprovar que as atividades pedagógicas foram realizadas em número superior se comparadas às demais. Isto prova que este grupo do Facebook é usado, essencialmente, como ferramenta pedagógica por seus integrantes. A prática docente tem, dessa forma, contribuído para que os alunos possam obter materiais pedagógicos antes do início das aulas, utilizando as tecnologias digitais de informação e comunicação (TDIC), conforme afirma Valente (2014), ao mostrar que as TDICs possibilitam uma transformação na educação. Ressaltamos aqui as ocorridas no ensino superior.

Os materiais a que os alunos têm acesso são estudados, num primeiro momento, em casa, para, posteriormente, serem trabalhados nas aulas. Isso configura a prática denominada de sala de aula invertida. Chamamos à atenção para o fato de que a maior parte de postagens foi atribuída à distribuição de material para estudo.

Este modelo pedagógico garante que os alunos tenham um melhor aproveitamento do tempo da aula, podendo tirar dúvidas, aprimorar os conhecimentos previamente obtidos, apresentar as teorias de que se apropriaram, enfim, obtendo melhores direcionamentos dos momentos pedagógicos com o professor para tratar de questões mais direcionadas, muitas vezes de forma prática e interativa, como postulado por Vigotsky (1988), ao considerar o processo de interação entre os sujeitos como central para a aquisição de conhecimentos.

Os alunos do mestrado têm usado o tempo das aulas, orientados pelos professores, para realizar discussões, apresentar seminários (em grupos ou individualmente), mostrando o que conseguiram assimilar. Os professores, por sua vez, fazem intervenções nas falas e nos trabalhos dos alunos, auxiliando-os sempre que necessário; esclarecem dúvidas e corrigem informações que não foram internalizadas satisfatoriamente.

Este modelo de ensino potencializa o aprendizado, uma vez que os alunos podem ter diferentes tipos de dificuldades na obtenção do conhecimento, sendo a ação pedagógica imprescindível nestes casos. Desde o momento em que os professores disponibilizam as atividades, eles também se colocam à disposição para o esclarecimento de eventuais dúvidas, chegando, por vezes, a fornecer atenção particular aos alunos, ampliando também o contato com eles, como comprovado nas próximas duas imagens: 
Figura 4: Professor solicitando o envio de trabalhos

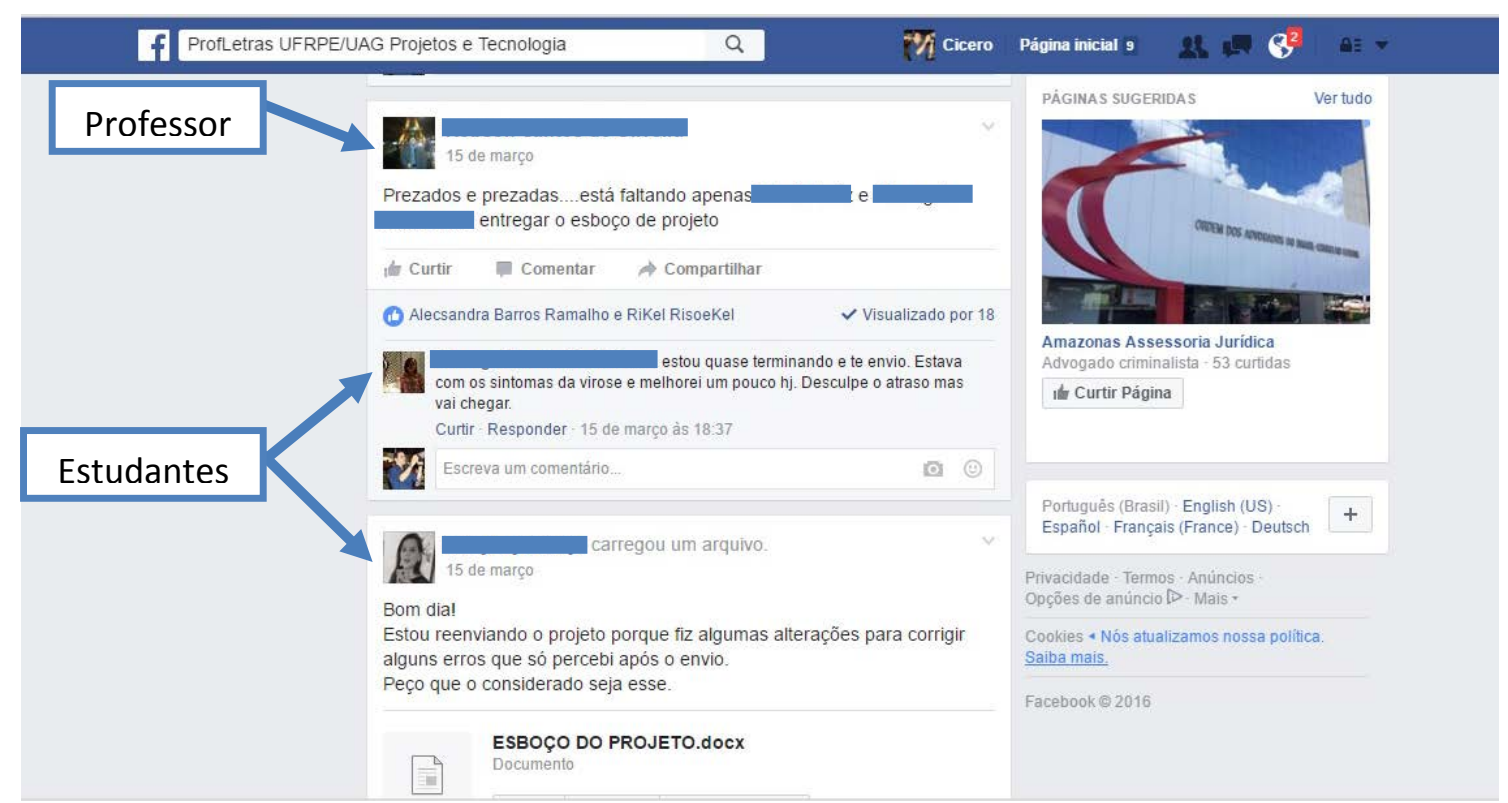

Observamos acima, na figura 4, que o professor apresenta aviso para os que ainda não entregaram a atividade (ver campo: Professor) e duas estudantes respondem ao chamado do professor (ver campo: Estudantes). Temos aqui um caso de interação online, a distância, quando o professor já tinha estabelecido prazos para entrega dos trabalhos e observou que alguns estudantes ainda não os tinham entregues. O ambiente virtual, nesse caso, permite uma interação online, não presencial, em caráter de acompanhamento pedagógico. A sociointeração, observada por Vigotsky (1988), explicita-se concretamente nas relações existentes neste ambiente, cuja didática acadêmica, pautada no modelo de sala de aula invertida, ultrapassa as fronteiras físicas da IES e permite maiores atuações (solicitações, esclarecimento de dúvidas, explicações, etc.) dos professores.

Ademais, apesar de o grupo ter sido criado pelo professor da disciplina Elaboração de Projetos/Tecnologias Educacionais, outros professores do curso, também inseridos no grupo, utilizaram o ambiente virtual para apresentar informações e material de estudo, como veremos a seguir.

$\mathrm{Na}$ figura seguinte verificaremos que o professor da disciplina Fonética e Fonologia enviou o material para as aulas subsequentes e preocupou-se em saber se todos os alunos do mestrado participavam do grupo; caso contrário, ele enviaria os textos para estudo da disciplina por e-mail. 
Figura 5: Professor disponibilizando material para as próximas aulas

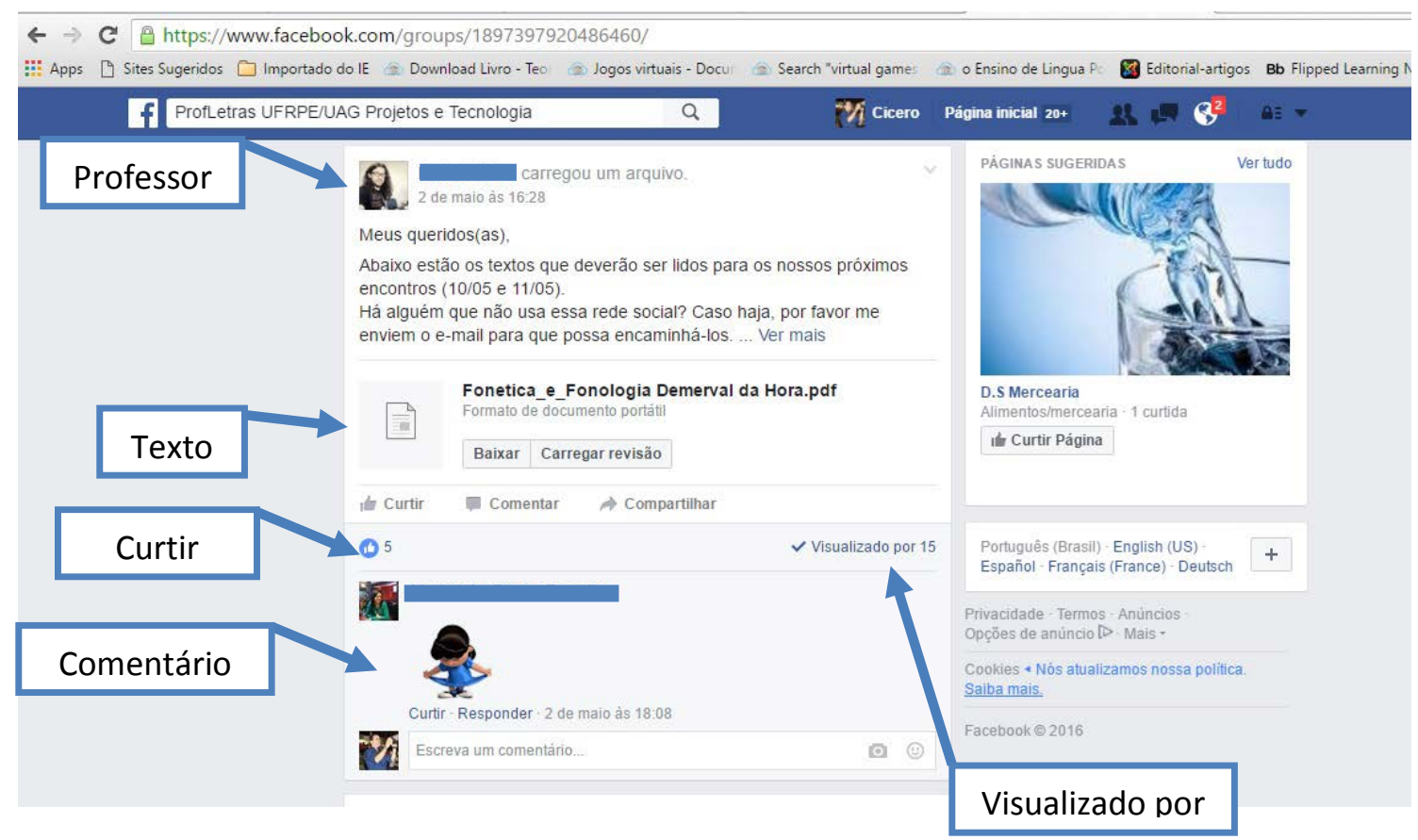

Nesse caso observamos como o professor pode monitorar as ações dos alunos. No recurso "Curtir", no campo de "Comentário" e principalmente no recurso "Visualizado por", é possível identificar quais estudantes leram a mensagem socializada pelo professor.

Outra professora utilizou também o grupo para disponibilizar os textos de estudos para debates em sala de aula. Vejamos a imagem a seguir:

Figura 6: Aluno postando material a pedido da professora

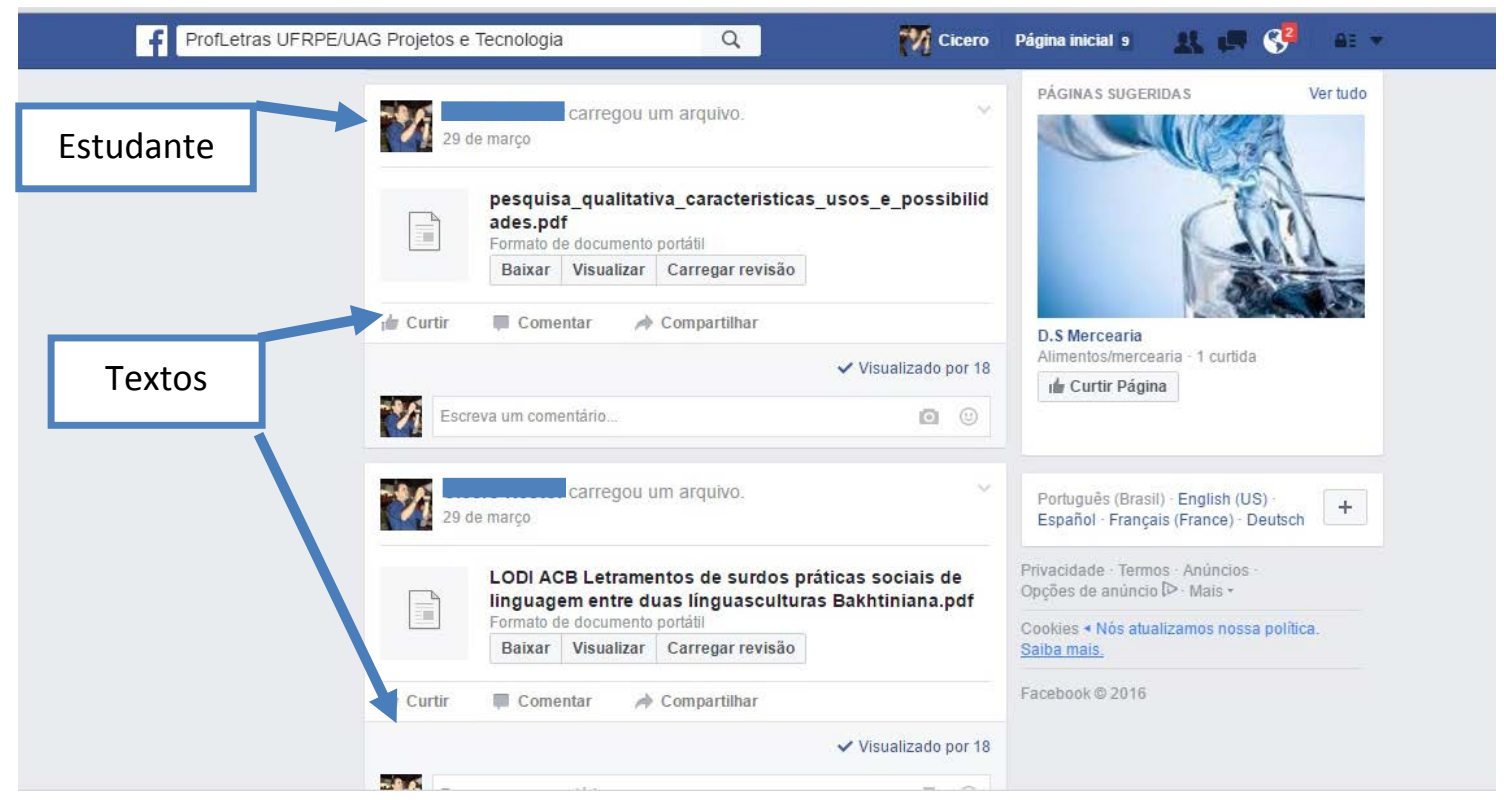


Como mostra a figura anterior (figura 6), foram disponibilizados dois textos, a pedido da professora, para que também fossem lidos em casa e trabalhados nas aulas posteriores. Vale ressaltar que a professora afirmou não ter a perícia necessária no manejo dessa ferramenta, por isso solicitou a um aluno que compartilhasse os textos com os demais. Neste caso, o estudante auxiliou a professora, realizando a postagem dos textos requisitados. Mais uma vez confirmase aqui o modelo da sala de aula invertida no ambiente virtual, permitindo o aspecto colaborativo.

Outra aplicação para o grupo do Facebook é a possibilidade de os alunos postarem seus trabalhos em vez de entregá-los presencialmente, fato que pode possibilitar ao professor mais tempo na sua correção, e, consecutivamente, promover orientações mais específicas, quando estas se fizerem necessárias. Este aspecto também faz parte do conceito de sala de aula invertida, pois possibilita ao professor não só manter o foco nas dificuldades apresentadas pelos alunos como também saber quais alunos necessitam de maior atenção no que se refere à apropriação dos conhecimentos estabelecidos.

Os alunos, por sua vez, podem enviar seus trabalhos nos prazos solicitados pelos professores, mesmo que as datas não possuam coincidência com as datas das aulas, uma vez que a distância, como já dito, seria um empecilho a se considerar, não fosse a RSV. Observemos a próxima imagem:

Figura 7: Envio de atividades pelos alunos

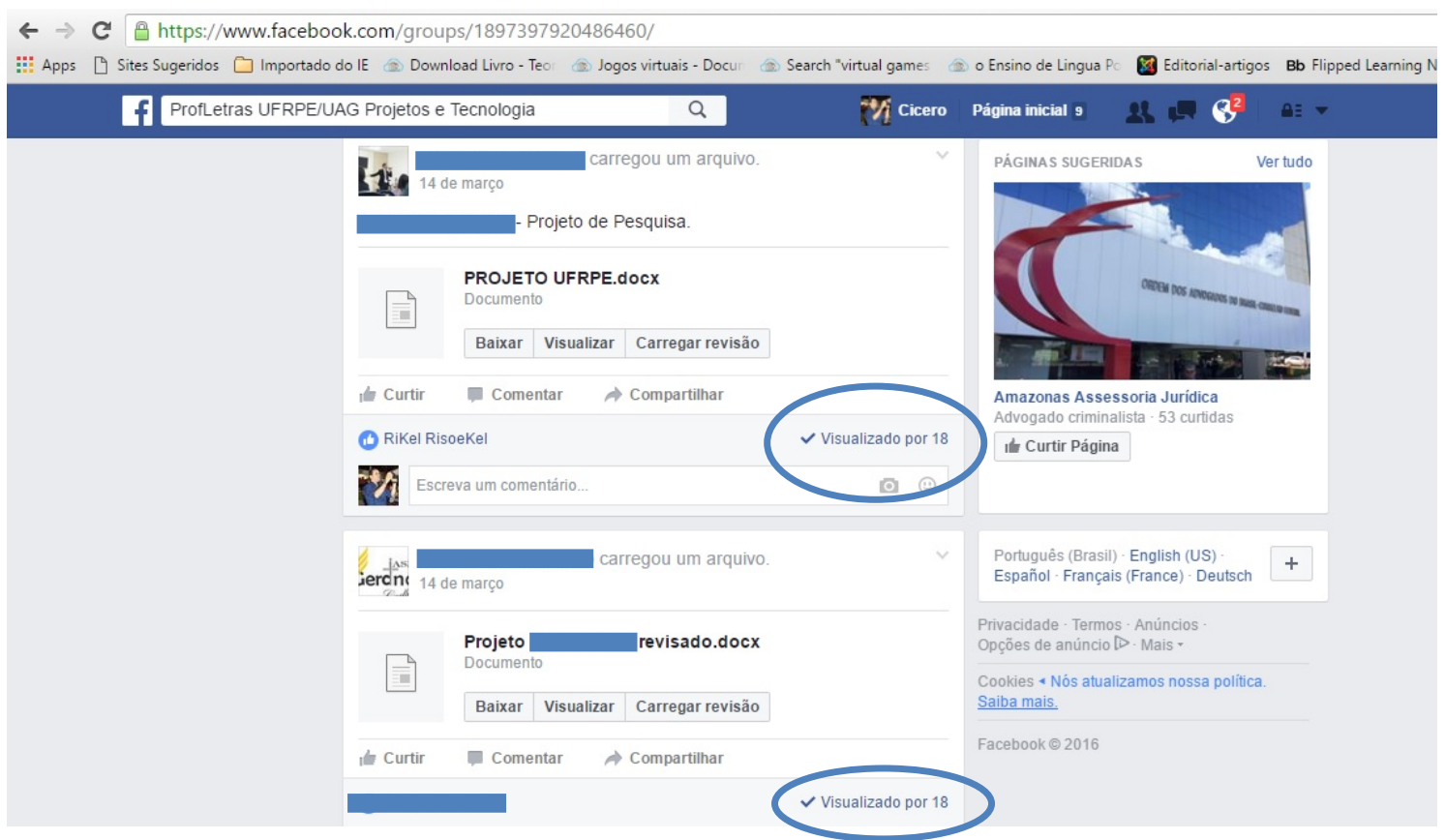


A figura 7 mostra dois alunos postando os trabalhos realizados. $O$ ambiente com o recurso "Visualizado por" permite ao professor, bem como a todos os membros do grupo, observar quem teve acesso (visualizou) o trabalho dos demais. Vemos, na figura 7, que ambos os trabalhos enviados tiveram visualização de 18 pessoas (sinalizado na figura pelas elipses).

O envio dos trabalhos, desde que dentro dos prazos estabelecidos pelos professores, podem ser postados a qualquer hora e ser realizado de qualquer lugar, maximizando a possibilidade de os alunos atenderem ao que thes foi proposto.

Os alunos têm trabalhado junto aos professores no que se refere a apropriação dos materiais, leituras em casa e reserva do espaço da aula para fomentar discussões, tirar dúvidas e aprimorar os conhecimentos já obtidos. As atividades aqui descritas são, segundo Oliveira (2015a), a "expansão da sala de aula", fato que contribui para uma formação mais integral dos indivíduos envolvidos neste processo.

Enfatizamos que o modelo de sala de aula invertida não dispensa a aula presencial e nem o modelo de ensino considerado tradicional, mas realiza uma mesclagem, um hibridismo de modelos. No modelo da sala de aula invertida não se dispensa a discussão em sala de aula e nem a atividade mediadora docente, e sim o oposto. Primordialmente, tais práticas se destacam, pois a leitura prévia dos textos favorecerá melhor condições de debates e discussões temáticas; ao mesmo tempo, uma visão e práxis mediadoras docentes devem estar presentes, tanto durante quanto além da aula presencial, pois caberá ao professor monitorar a movimentação de estudantes com as atividades propostas, as leituras realizadas e os resultados esperados, tanto no ambiente virtual quanto em sala de aula. Os professores, ao optarem por este modelo, poderão, inclusive, preparar intervenções pedagógicas mais pontuais, mais condizentes com as necessidades dos(as) alunos(as). Ressalta Oliveira (2015, p. 148) que "um novo perfil de educação e de educador se desenha nos dias atuais em que predominam as tecnologias emergentes tanto dentro quanto fora da Internet: a chamada cibercultura". Entendemos que os trabalhos aqui relatados fazem parte de práticas pedagógicas includentes, visando ao real desenvolvimento das potencialidades dos alunos.

Registramos, assim, a prática entendida como sala de aula invertida que utiliza o ambiente das RSV como o Facebook, promovendo acesso, difusão e 
$\mathbb{P}_{\text {๖isse }} \mathcal{A}$

compartilhamento dos conhecimentos obtidos, bem como a interação entre os participantes do grupo (professor e estudantes).

\section{Conclusão}

Concluímos que as práticas pedagógicas aliadas ao uso do Facebook conseguem atender às expectativas de difusão do conhecimento. Valente (2014) aponta que várias IES têm empregado, com êxito, as técnicas da sala de aula invertida. Esse fato também pôde ser comprovado pela análise dos dados aqui exibidos por meio da aplicação de uma pesquisa com metodologia exploratóriodescritiva, quantitativa, com método de coleta de dados por meio do estudo de campo que, segundo Gil (2002, p. 53), é desenvolvido “(...) por meio da observação direta das atividades do grupo estudado (...)". Chegamos à conclusão, tal como proposta por Oliveira (2015), de que as práticas educacionais, aliadas aos recentes recursos tecnológicos disponíveis, não podem mais ser desconsideradas.

O uso do Facebook proporciona um suporte atraente e significativo para os processos de ensino-aprendizagem, em especial porque, para os alunos do Profletras, tal ferramenta tem encurtado distâncias, motivado os estudos e, segundo Moreira (1999), ao trazer as contribuições de Vigotsky, proporciona a promoção do ensino que se consuma quando o professor e o aluno partilham significados. Tal partilha, maximizada nas aulas, deve grande parte de seu êxito devido ao modelo de sala de aula invertida, empregado na experiência em questão.

Para Pereira (2007), todos os agentes do ambiente educacional estão sujeitos às mudanças promovidas pelas novas tecnologias, sendo necessária a transformação dos hábitos pedagógicos como resposta às mudanças e aos desafios que se impõem na era digital. Tais mudanças não ficaram, segundo o exposto, apenas no campo da inovação tecnológica, mas possibilitaram um contato mais intenso entre professores e alunos, que pode ser realizado com uma frequência significativamente maior, diferentemente do modelo de aulas pautadas apenas nos hábitos tradicionais, e entre os próprios alunos, que podem partilhar experiências, reunirem-se em grupos (mesmo estando a quilômetros de distância), esclarecer suas dúvidas, enfim, obter uma assistência mais personalizada nos processos de aprendizagem. 
Ressaltamos, portanto, as vantagens dessa prática na construção de uma vida acadêmica mais rica em significados e elos interpessoais.

\section{Referências}

BACICH, Lilian; TANZI NETO, Adolfo; TREVISAN, Fernando de Mello (Org.). Ensino Híbrido: personalização e tecnologia na educação. Porto Alegre: Penso, 2015.

GIL, Antonio Carlos. Como elaborar projetos de pesquisa. São Paulo: Átlas, 2002.

MOREIRA, Marco Antônio. Teorias de aprendizagem. São Paulo: EPU, 1999.

OLIVEIRA, Robson Santos de. Práticas pedagógicas utilizando as redes sociais virtuais. In: LIMA, Maria Socorro Lucena (org). Didática e a prática de ensino na relação com a escola - coleção práticas educativas. Fortaleza: EdUECE, 2015a. Livro 1. Disponível em: <http://www.uece.br/endipe2014/ebooks/livro1/>. Acesso em 10 mai. 2016.

. Cibercultura e Educação. In: PEREIRA, Jose Alan da Silva; COSTA, Maria de Fátima Batista (orgs). Saberes Múltiplos. Recife: Ed. dos Organizadores, 2015b.

PEREIRA, João Thomaz. Educação e sociedade da informação. In: COSCARELLI, Carla; RIBEIRO, Ana Elisa (orgs). Letramento digital: aspectos sociais e possibilidades pedagógicas. 2.ed. Belo Horizonte: Autêntica, 2007.

VALENTE, José Armando. Blended learning e as mudanças no ensino superior: a proposta da sala de aula invertida. In: Educar em Revista. Curitiba: Editora UFP. Edição Especial, n. 4, 2014. Disponível em: <https://www.researchgate.net/ publication/276106919_Blended_learning_e_as_mudancas_no_ensino_superior_a_ proposta_da_sala_de_aula_invertida > Acesso èm 03 abr. $\overline{2} 01 \overline{6}$.

XAVIER, Antonio Carlos dos Santos. Letramento digital e ensino. In: SANTOS, Cami Ferraz; MENDONÇA, Márcia (ogs). Alfabetização e letramento: conceitos e relações. Belo Horizonte: Autêntica, 2007. 